\title{
Immunological aspects of atherosclerosis
}

\section{By D. F. Davies, Department of Pathology, West Wales General Hospital, Carmarthen $S_{3}{ }_{3} 2 A F$}

A vast amount of research has been carried out attempting to determine the causes of atheroma and coronary heart disease (CHD). Certain so-called 'risk factors' have been identified but these have failed to provide a satisfactory explanation of the pathological changes found. Frequently CHD occurs, even in young people, when no known risk factor is present. Prediction studies (Keys, Aravanis, Blackburn, van Buchem, Buzina, Djordjevic, Fidanza, Karvonen, Menotti, Puddu \& Taylor, 1972) have led to the conclusion that the incidence of CHD is strongly influenced by one or more unknown factors.

In accepting that we have failed to solve many basic problems in the field of atheroma and CHD, it becomes essential to search for the fundamental reasons for this failure. This may be even more important than the further accumulation of factual knowledge of dubious relevance to these diseases. Study of research communications suggests a failure to realize the inadequacy of existing concepts and there appears to be ignorance of assumptions which have been made and therefore ignorance of the validity or relevance of the conclusions drawn. Prevalent is the idea that research is based solely upon facts. Medawar (1967) has written: 'Unfortunately, we have been brought up to believe that scientific discovery turns upon the use of ... a logically mechanized process of thought which, starting from simple declarations of fact arising out of the evidence of the senses, can lead us with certainty to the truth of general laws'. But as Medawar further points out, this type of research is only one aspect of the scientific process. A further aspect is conceptual development providing a basis which will indicate the direction further research should take. Popper's view (1959) is that observation cannot be prior to theory because some theory is presupposed by any observations.

The two processes, conceptual development and factual accumulation, are interdependent and of little value alone. There is a need for a concept to relate facts one to another. It is surprising that two diverse concepts of atherogenesis have fundamentally changed little for over a hundred years despite vast progress in the accumulation of facts. The thrombogenic hypothesis, reformulated by Duguid (I949), originated with von Rokitansky (1844). This hypothesis does not appear to be more than a description of a process which may contribute to atheroma. A second hypothesis, originated by Virchow (1862), relates atheroma to imbibition of plasma constituents, including lipid and fibrinogen, into the arterial wall. It is supported by evidence that the arterial wall is abnormally permeable in atheroma. The imbibition hypothesis is related to the widely held view that atheroma and coronary heart disease are in some way the results of disturbed lipid metabolism. Other hypotheses of atherogenesis have offered little more than commentaries on certain limited aspects. 
There may well be need for the 'bridge-building' intellectual process known as heuristic logic, in which conceptual development is not entirely based upon facts because the data are not available. Heuristic processes, with the creation of intermediate guesswork, may provide a useful 'bridging' device for a concept.

It was as a result of such considerations that I decided in 1968 to study food antibodies in CHD. This study led to the report of a relationship between circulating serum antibodies to cow's milk and CHD (Davies, Davies \& Richards, 1969) and to the formulation of the immunological hypothesis (Davies, 1969). The findings were considered by some to be bizarre, presumably because they could not be explained by existing concepts.

To use contemporary phraseology, these antibodies are newly discovered 'risk factors'. But they are more than this, for the relationship is evidence of an immunological mechanism. The persistence of food antibody in the circulation is evidence of repeated absorption of the related food in antigenic form and presumably the formation of circulating antigen-antibody complexes. The action of such complexes is well established. In brief they are capable of damaging vascular endothelium, and promoting platelet stickiness, adherence and intravascular thrombosis. They can cause fibrin deposition. Antigen-antibody complexes can cause the release of substances capable of increasing vascular permeability. An immunological mechanism in atherosclerotic cardiovascular disease could, however, operate in several ways, either directly through the formation of complexes, through disturbance of complement, or indirectly by action on platelets and fibrinogen.

It was clearly necessary to seek confirmation that a relationship did exist between cow's milk antibodies and CHD. This led to cooperation with Dr P. C. Elwood of the MRC Epidemiological Unit in Cardiff. In our studies (Davies, Johnson, Rees, Elwood \& Abernethy, 1974) the presence and level of serum antibody to reconstituted, heat-dried cow's milk, boiled egg white and gluten were determined in 216 patients who had had a myocardial infarction (MI) and in 144 control hospital patients. A higher proportion of MI patients than controls had antibodies to dried milk and probably to egg, but not to gluten. These differences in proportion were very striking in the MI patients who died within 6 months of infarction. The possession of antibody to cow's milk protein and egg white in blood samples taken soon after infarction seems, therefore, to be highly predictive of death. Mortality was increased almost threefold if either antibody was present. The evidence supports the concept that the lifelong absorption of antigenic food protein in susceptible individuals is a cause of atheroma and CHD.

There are facts which are not explained by the lipid concept of CHD. For example, myocardial mast-cell proliferation is associated with coronary thrombosis and infarction (Paterson \& Mills, 1958; Pomerance, 1958). The first phase of atherogenesis is associated with the proliferation of smooth muscle cells (Scott, Daoud, Wortman, Morrison \& Jarmolych, 1966). There is a relationship between CHD and hypertension. Could the relationship be due to this smooth muscle-cell proliferation? There is evidence that the appearance of lipids in the arterial intima 
is a secondary phenomenon preceded by intimal oedema (Gerö, I969). The immunological hypothesis offers an explanation both for these facts and also for those which until now have formed the bases for the thrombogenic and imbibition hypothesis. (See the review by Poston \& Davies (1974)).

An important subject which may well be related to this work is that of the artificial feeding of babies with cow's milk. Nearly all infants fed with cow's milk receive an antigenic stimulation by its proteins and become sensitized to varying degress (Gunther, Aschaffenburg, Mathews, Parish \& Coombs, 1960). Breast milk does not appear to have any such comparable effect. The age at which exposure to the antigenic influence of cow's milk protein first occurs influences the immunological response. For there is evidence that breast-feeding results in a lower serum antibody level to cow's milk protein, when this is ingested later in life, than does artificial feeding with cow's milk products (Gunther, et al. 1960; Gunther, Cheek, Mathews \& Coombs, 1962).

It is possible that these findings are related to those of Osborn (1968). He reported that the mothers of rog young individuals whose coronary arteries had been studied at autopsy were questioned about postnatal feeding. Where there had been no breast-feeding he found that the coronary arteries were mainly abnormal. Those with at least 2 months breast-feeding mostly had normal coronary arteries. Thought must now be given to the possibility that artificial feeding with heat-dried cow's milk preparations is creating an immunological basis for atherosclerotic disease.

\section{REFERENCES}

Davies, D. F., Davies, J. R. \& Richards, M. A. (1969). 7. Atheroscler. Res. 9, I03.

Davies, D. F. (1969). F. Atheroscler. Res. 10, 253.

Davies, D. F., Johnson, A. P., Rees, B. W. G., Elwood, P. C. \& Abernethy, M. (1974). Lancet i, IOI2.

Duguid, J. B. (1949). Lancet ii, 925.

Gerö, S. (1969). In Atherosclerosis: Pathology, Physiology, Aetiology, Diagnosis and Clinical Management, p. 455 [F. G. Schettler and G. S. Boyd, editors]. Amsterdam: Elsevier.

Gunther, M., Aschaffenburg, R., Mathews, R. H., Parish, W. E. \& Coombs, R. R. A. (1960). Immunology 3, 296.

Gunther, M., Cheek, R., Mathews, R. H. \& Coombs, R. R. A. (I962). Int. Archs Allergy appl. Immun. 21, 257.

Keys, A., Aravanis, C., Blackburn, H., van Buchem, F. S. P., Buzina, R., Djordjevic, B. S., Fidanza, F., Karvonen, M. J., Menotti, A., Puddu, V. \& Taylor, H. L. (1972). Circulation 45, 815.

Medawar, P. B. (1967). The Art of the Soluble, p. I 13. London: Methuen.

Osborn, G. R. (1968). Colloques int. Cent. natn. Rech. scient. no. I69.

Paterson, J. C. \& Mills, J. (1958). Archs Path. 66, 335.

Pomerance, A. (1958). F. Path. Bact. 76, 55.

Popper, K. (1959). The Logic of Scientific Discovery. London: Hutchinson.

Poston, R. N. \& Davies, D. F. (1974). Atherosclerosis 19, 353.

Scott, R. F., Daoud, A. S., Wortman, B., Morrison, E. S. \& Jarmolych, J. (1966). J. Atheroscler. Res. 6, 499.

Virchow, R. (1862). Gesammelte Abhandlungen sur wissenschaftlichen Medixin, p. 500. Berlin: Max Hirsch. (Translated by H. Hauffe.)

Von Rokitansky, C. (1844). Handbuch der pathologischen Anatomie, vol. 2. Vienna: Braunmuller und Seidel. 